\title{
An experimental methodology for the concurrent characterization of multiple parameters influencing nanoscale friction
}

\author{
Marko PERČIĆ ${ }^{1,2}$, Saša ZELENIKA ${ }^{1,2,}$, Igor MEZIĆ ${ }^{2,3}$, Robert PETER ${ }^{2,4}$, Nikša KRSTULOVIĆ \\ ${ }^{1}$ University of Rijeka, Faculty of Engineering, Vukovarska 58, Rijeka 51000, Croatia \\ ${ }^{2}$ University of Rijeka, Centre for Micro- and Nanosciences and Technologies, Radmile Matejčić 2, Rijeka 51000, Croatia \\ ${ }^{3}$ Department of Mechanical Engineering, UC Santa Barbara, Santa Barbara, CA 93105, USA \\ ${ }^{4}$ University of Rijeka, Department of Physics, Radmile Matejčić 2, Rijeka 51000, Croatia \\ ${ }^{5}$ Institute of Physics, Bijenička 46, Zagreb 10000, Croatia \\ Received: 08 January 2019 / Revised: 18 February 2019 / Accepted: 15 March 2019 \\ (C) The author(s) 2019.
}

\begin{abstract}
A structured transdisciplinary method for the experimental determination of friction in the nanometric domain is proposed in this paper. The dependence of nanoscale friction on multiple process parameters on these scales, which comprise normal forces, sliding velocities, and temperature, was studied via the lateral force microscopy approach. The procedure used to characterize the stiffness of the probes used, and especially the influence of adhesion on the obtained results, is thoroughly described. The analyzed thin films were obtained by using either atomic layer or pulsed laser deposition. The developed methodology, based on elaborated design of experiments algorithms, was successfully implemented to concurrently characterize the dependence of nanoscale friction in the multidimensional space defined by the considered process parameters. This enables the establishment of a novel methodology that extends the current state-of-the-art of nanotribological studies, as it allows not only the gathering of experimental data, but also the ability to do so systematically and concurrently for several influencing variables at once. This, in turn, creates the basis for determining generalizing correlations of the value of nanoscale friction in any multidimensional experimental space. These developments create the preconditions to eventually extend the available macro- and mesoscale friction models to a true multiscale model that will considerably improve the design, modelling and production of MEMS devices, as well as all precision positioning systems aimed at micro- and nanometric accuracy and precision.
\end{abstract}

Keywords: nanoscale friction; lateral force microscopy; experimental determination methodology; multivariate space; contact mechanics

\section{Introduction}

A widely recognized cause of failure of micro- and nano-electromechanical devices (MEMS and NEMS, respectively), comprising relative motion of the constituting elements, is friction. In fact, miniaturization implies a growth of the surface-to-volume ratio, thus inducing a scale-dependent increase of the importance of friction and adhesion and their prevalence over volumetric forces. Relying on the old-fashioned models of friction results in insufficient precision for micronor submicron-sized devices, where the mechanisms influencing friction are different from those dominating friction on the macroscale. Nanotribology is therefore essential in establishing a basic understanding of interfacial phenomena in MEMS and NEMS devices, as well as computer storage devices and other applications. In addition, devices characterized by microand nanopositioning precision are often required in precision engineering, as well as in micro- and

* Corresponding author: Saša ZELENIKA, E-mail: sasa.zelenika@riteh.hr 


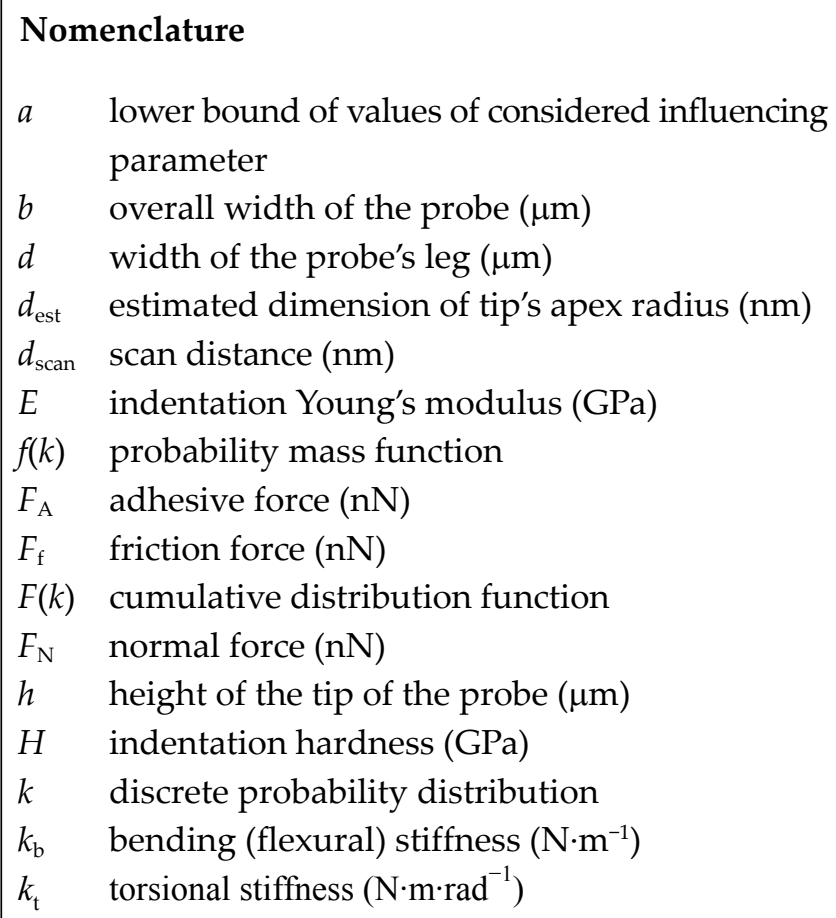

$L^{\prime} \quad$ probe's length $(\mu \mathrm{m})$

$L_{1} \quad$ vertical length of the slot in the probe $(\mu \mathrm{m})$

$n$ number of homogeneously spaced values in the Voronoi subdivision of the experimental space

$r \quad$ radius of the apex of the tip of the probe $(\mu \mathrm{m})$

$R_{\mathrm{a}} \quad$ arithmetic average surface roughness (nm)

$R_{\mathrm{q}} \quad$ root mean square roughness (nm)

$R_{Z} \quad$ maximum height of profile (nm)

$v \quad$ sliding velocity $(\mathrm{nm} / \mathrm{s})$

$t \quad$ thickness of probe's cantilever $(\mu \mathrm{m})$

$x, y$ position of the tip of the probe with respect to the free end of the respective cantilever $(\mu \mathrm{m})$

$z \quad$ upper bound of values of considered influencing parameter

$\alpha \quad$ slope of the edge of the probe $\left(^{\circ}\right)$

$\vartheta \quad$ temperature $\left({ }^{\circ} \mathrm{C}\right)$

$\varphi$ angle defining the inclination of the legs of the probe $\left(^{\circ}\right)$ nanosystem technologies; the accuracy of these devices is again often limited by frictional effects with their stochastic nonlinear characteristics [1-3].

While frictional phenomena on the macro- and mesoscales are well described and their effects can be simulated via suitable models [4-7], as well as generally efficiently compensated by employing proper control techniques [3, 7-9], the available friction models do not take into account true nanometric motion or scaling phenomena related to friction. In fact, the understanding of friction at the level of atomic interactions has only been enabled in the last two decades or so by the affordable availability of scanning probe microscopy (SPM) methods [1, 10]. The available studies are, however, mostly limited to the characterization of the dependence of nanoscale friction on a single or, in the best cases, two influencing parameters at a time [11, 12]. In addition, in some of the recent comprehensive studies [13], nanoscale frictional phenomena are related to normal forces and sliding velocities that are a few orders of magnitude larger than those considered in this study, while contact mechanics analyses are based on Hertz contact equations. The theory of Hertz contacts could, however, be inappropriate even for elastic contacts occurring in herein considered cases, since for very accurate calculations a lengthy iterative evaluation of transcendental equations involving elliptic integrals has to be adopted or else significant errors could occur [14]. A clear need for the extension of SPM experimental studies to the concurrent validation of the influence of multiple variable parameters on true nanoscale friction is thus evident [15].

A structured transdisciplinary methodology for the experimental determination of friction in the nanometric domain is hence proposed in this work. The dependence of nanoscale friction on multiple process parameters on these scales, comprising normal forces, sliding velocities and temperature, was thus studied. In fact, the basic standard macro- and mesoscale friction models, such as Amonton, Coulomb or the Stribeck models, establish the importance of the dependence of friction on normal forces and velocities, whereas temperature influences the physical state of the surfaces in relative motion. Newer studies indicate, moreover, a very intricate and often nonlinear dependence of friction at the micro- and nanoscales on velocity and temperature as well as on normal loads [1]. In the herein considered case, the proposed methodology, which is based on elaborated design of experiments (DoE) algorithms, was thus used on this set of basic influencing parameters that have the biggest and most 
immediate technological impact, although it is valid for any multivariate experimental space of parameters influencing nanofriction. The methodology was thus successfully implemented to concurrently characterize the dependence of nanoscale friction in the multidimensional space defined by the herein considered process parameters.

The described protocols establish a novel methodology extending the current state-of-the-art of nanotribological studies, as they allow not only the gathering of experimental data, but also the ability to do so systematically and concurrently for several influencing variables at once. This, in turn, creates the basis for determining generalizing correlations of the value of nanoscale friction in any multidimensional experimental space. All of this creates the preconditions to eventually extend the available macro- and mesoscale friction models to a true multiscale model that will considerably improve the design, modelling and production of MEMS devices, as well as all precision positioning systems aimed at micro- and nanometric accuracy and precision.

\section{Experimental methodology}

Measurements of the values of the friction force on the thin-film samples were performed by using the Bruker Dimension Icon SPM [16] available at the Centre for Micro- and Nanosciences and Technologies (NANORI) of the University of Rijeka, Croatia [17]. The measurements were controlled by using the respective NanoScope hardware and software.

Dry (unlubricated) contacts were thus characterized by using the lateral force contact measurement mode (LFM) of the device (shown schematically in Fig. 1) in air, thus approaching habitual technological conditions. Lateral (transversal) scans were performed on $500 \mathrm{~nm} \times$ $500 \mathrm{~nm}$ surfaces of the analyzed samples, inducing torsion of the cantilever bearing the measurement tip (hereafter this assembly is designated as "probe"). The resulting voltages were converted to values of the lateral (transversal) force exerted on the sample by calibrating the mechanical behavior of the probe itself.

The resulting measurement procedure followed in this work is shown schematically in Fig. 2. The method involves the calibration of the stiffness of the probe in both the lateral and normal directions. The

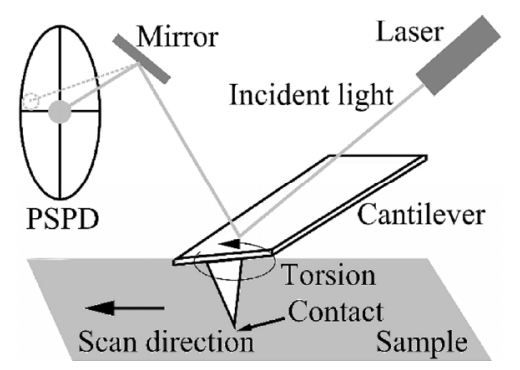

Fig. 1 Scheme of the LFM measurement configuration.

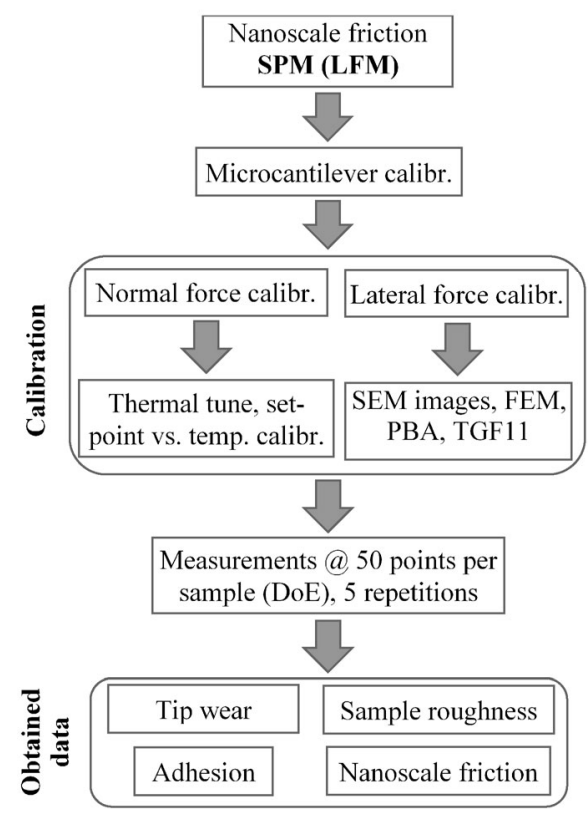

Fig. 2 Proposed experimental methodology of obtaining nanoscale friction by using LFM.

calibration of the normal (flexural) stiffness of the cantilever is important for obtaining a precise value of the normal forces exerted on the samples. The calibration of the cantilever's lateral (torsional) stiffness is, in turn, important for interpreting the LFM signals and thus attaining a meaningful and accurate data analysis of the performed scans, i.e., in order to obtain the effective values of the friction force. The diverse considered parameters influencing concurrently nanoscale friction, and their respective value ranges, were:

- normal force $F_{\mathrm{N}}=10-150 \mathrm{nN}$,

- sliding velocity $v=5-500 \mathrm{~nm} / \mathrm{s}$,

- temperature $\vartheta=20-80{ }^{\circ} \mathrm{C}$.

The analyzed samples were: aluminum oxide (alumina or $\mathrm{Al}_{2} \mathrm{O}_{3}$ ), titanium dioxide $\left(\mathrm{TiO}_{2}\right)$, molybdenum disulphide $\left(\mathrm{MoS}_{2}\right)$ and aluminum (Al). In fact, $\mathrm{Al}_{2} \mathrm{O}_{3}$ has not only good mechanical properties (especially hardness and strength), for which it is 
broadly used in MEMS technology (e.g., in packaging of MEMS devices) and in integrated circuit (IC) technology, but it is also used in a thin-film form for coatings in implants, insulating applications and when wear is to be minimized. On the other hand, $\mathrm{TiO}_{2}$ is broadly used in MEMS technology for optical elements, such as filters and mirrors, or as a biocompatible coating in implants (e.g., dental implants). $\mathrm{MoS}_{2}$ is a typical material with good lubricating properties, although it is also used in nanotechnology for its electrical properties. Finally, aluminum, next to being the most widely used non-ferrous metal, is used as a thin film for electrical contacts and interconnectors, reflective surfaces (e.g., in the Texas Instruments' Digital Light Processor (DLP) device) or in micromechanical components.

The basic mechanical properties of the thin films used, as determined on a Keysight G200 Nanoindenter [16] via standardized measurements by using a 20-nm Berkovich tip, are reported in Table 1.

These samples were scanned at 50 different measurement points along 256 scan lines with varying influencing parameters, while, for uncertainty and error analysis, in each point the measurements were repeated five times.

The distribution of measurement points in the considered experimental space was determined by using a structured design of experiments (DoE) approach. Standard DoE methods such as (full) factorial design, split-plot design, linear regression, Monte Carlo, Taguchi or Box-Behnken [18, 19] are, however, poorly suited to obtain a detailed insight into the studied multidimensional stochastic phenomenon. In fact, these approaches are commonly aimed at conventional industrial practices where results are generally limited to the values of the control variables inducing local extrema of the dependent variable [19]. Since recent studies indicate, in turn, marked advantages in terms of the space filling properties

Table 1 Determined indentation Young's modulus $E$ and hardness $H$ of the used thin film samples.

\begin{tabular}{ccc}
\hline & $E(\mathrm{GPa})$ & $H(\mathrm{GPa})$ \\
\hline $\mathrm{Al}_{2} \mathrm{O}_{3}$ & $152.89 \pm 10.93$ & $13.44 \pm 0.93$ \\
$\mathrm{TiO}_{2}$ & $119.15 \pm 9.96$ & $8.01 \pm 0.62$ \\
$\mathrm{MoS}_{2}$ & $148.04 \pm 16.31$ & $10.06 \pm 1.09$ \\
$\mathrm{Al}$ & $61.84 \pm 14.36$ & $4.95 \pm 0.85$ \\
\hline
\end{tabular}

of an approach where DoE is conducted by using centroidal Voronoi tessellation (CVT) sampling [20-22], and CVT is efficiently implemented in the commercially available GoSumD software [23], CVT was used to determine the sample points in the considered multidimensional process parameters' space [24]. Given then a set of desired points ("generators") and a distance function from each generator to its mass centroid, Voronoi tessellations are subdivisions of the experimental space. The variation of the influencing parameters was defined via a discrete uniform distribution, i.e., a distribution where a finite number $n$ of homogeneously spaced values has the same probability to be observed [20,21,23]. The integer parameters of the distribution are:

$$
n=z-a+1
$$

where $a$ and $z$ are the lower and upper bounds of the values of the considered influencing parameter, respectively. The distribution of sample points was thus generated by a discrete probability distribution $k$ attained by using a probability mass function $f(k)$ defined in Eq. (2). On the other hand, the cumulative distribution function $F(k)$, given by Eq. (3), was used to specify the placement of multivariate random variables (i.e., the points in the considered multi-dimensional influencing parameters' space) [21, 23, 24]:

$$
\begin{gathered}
f(k)= \begin{cases}1 / n & \text { if } a \leq k \leq z, \\
0 & \text { otherwise }\end{cases} \\
F(k)= \begin{cases}0 & \text { if } k<a, \\
\frac{[k]-a+1}{n} & \text { if } a \leq k<z, \\
1 & \text { if } k>z\end{cases}
\end{gathered}
$$

Given a density function, the center of mass of each subset making up a Voronoi tessellation can thus be determined. However, as the locations of the generators do not generally coincide with the centers of mass of the data subsets, distinct Voronoi tessellations called CVTs are used to assure the convergence of these locations [24] and determine the 50 measurement points in the considered multidimensional experimental space defined by the range of variation of the process parameters $F_{\mathrm{N}}, v$ and $\vartheta$ (see Appendix 1).

It should be noted that, since the performed 
measurements are conducted in air, the friction force is dependent on the adhesion between the probe and the samples, on surface roughness, as well as on the contact area of the probe with the sample [25]. The samples were therefore analyzed using the SPM device by employing conventional contact-mode atomic force microscopy (AFM) so as to obtain the respective surface roughness and determine the adhesion forces. Special attention was dedicated to the study of the wear of the tip of the probe itself, which has a marked influence on the adhesion that is superimposed on the normal loads inducing the friction forces. The variability of adhesion due to temperature was determined for each sample by using the Peak Force Quantitative Nanomechanical Mapping (PF-QNM ${ }^{\circledR}$ ) measurement mode of the Bruker's SPM device.

In the following sections of this paper, all the phases of the adopted structured engineering approach to the experimental determination of nanoscale friction will be thoroughly described.

\section{Synthesis and characterization of the samples}

The $\mathrm{Al}_{2} \mathrm{O}_{3}$ and $\mathrm{TiO}_{2}$ samples used in this work were synthetized via atomic layer deposition (ALD) technology (principally shown in Fig. 3(a)), using the thermal mode on a Beneq TFS 200 device [16] available again at the NANORI facilities of the University of Rijeka, Croatia [17]. The employed precursors were trimethylaluminum $\left(\mathrm{Al}\left(\mathrm{CH}_{3}\right)_{3}\right)$ and titanium-tetrachloride $\left(\mathrm{TiCl}_{4}\right)$, for $\mathrm{Al}_{2} \mathrm{O}_{3}$ and $\mathrm{TiO}_{2}$, respectively, in combination with water $\left(\mathrm{H}_{2} \mathrm{O}\right)$ vapor, while high-purity nitrogen (purity 6.0) was used as the purging gas. The deposition of $\mathrm{Al}_{2} \mathrm{O}_{3}$ was carried out at $200{ }^{\circ} \mathrm{C}$ with the following ALD cycle: a $180-\mathrm{ms}-\mathrm{Al}\left(\mathrm{CH}_{3}\right)_{3}$ pulse was followed by a 1-s purge, then a $180-\mathrm{ms}-\mathrm{H}_{2} \mathrm{O}$ pulse was followed, again, by a 1-s purge. For the $\mathrm{TiO}_{2}$ deposition at $150{ }^{\circ} \mathrm{C}$ (a)

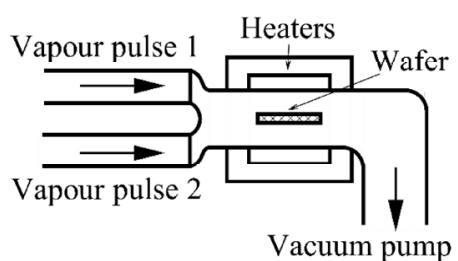

(b) Laser pulse

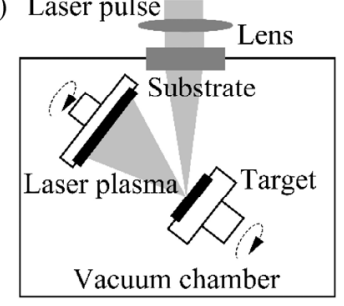

Fig. 3 Scheme of the ALD (a) and of the PLD (b) processes. the pulsing times for $\mathrm{TiCl}_{4}$ and $\mathrm{H}_{2} \mathrm{O}$ were $250 \mathrm{~ms}$ and $180 \mathrm{~ms}$, respectively, followed by purging cycles of 3 and $2 \mathrm{~s}$, respectively [24].

The $\mathrm{Al}$ and $\mathrm{MoS}_{2}$ samples were obtained at the Institute of Physics in Zagreb, Croatia, by using pulsed laser deposition (PLD) [26], shown principally in Fig. 3(b). The Nd:YAG laser parameters employed in the PLD process were: a wavelength of 1,064 nm, pulse duration of $4 \mathrm{~ns}$ at a $5 \mathrm{~Hz}$ repetition rate and a pulse energy of $340 \mathrm{~mJ}$. Laser pulses were focused on the target that was parallel to the silicon (Si) substrate and inclined by $45^{\circ}$ with respect to the impinging laser beam, yielding a fluence of $18 \mathrm{~J} / \mathrm{cm}^{2} .5,000$ laser pulses were used to obtain the desired film thickness of several tens of nanometers. The distance between the target, which was rotated to avoid drilling and increase the films' homogeneity, and the substrate was $3 \mathrm{~cm}$. Both the target holder and the substrate were kept on a floating potential at room temperature in a high vacuum environment $\left(<10^{-3}\right.$ mbar) [24].

Prior to the actual measurements, the obtained thin-film samples were characterized at the NANORI facilities [17]. X-ray photoelectron spectroscopy (XPS) using a SPECS XPS device [27] and a Hiden secondary ion mass spectrometer (SIMS) work station [16] were used. The XPS spectra were thus measured via the spectrometer of the XPS device, which is equipped with a hemispherical energy analyzer (PHOIBOS 100 MCD-5) and a monochromatized source of $\mathrm{Al} \mathrm{K \alpha}$ $\mathrm{X}$-rays of up to $1,486.74 \mathrm{eV}$. The typical XPS measurement vacuum level during the performed analyses was in the $10^{-9} \mathrm{mbar}$ range. The obtained photoemission spectra, whose background was subtracted, were fitted with sets of Gaussian-Lorentzian functions. The measurements allowed establishing that the sample films were of high purity, and that a thin (few atomic monolayers) oxide film was formed on their surface. The latter was characterized by a spectral contribution induced by $\mathrm{O}-\mathrm{H}$ or $\mathrm{O}-\mathrm{C}$ bonds; there is also a tendency towards the formation of surface hydroxide $\mathrm{OH}$ groups [28].

On the other hand, the Hiden SIMS device is equipped with two ion guns, a quadrupole mass analyzer and a residual gas analyzer (RGA), allowing in-depth profiles to be obtained by using $3 \mathrm{keV} \mathrm{Ar}^{+}$ primary ion beams impinging at $45^{\circ}$, while collecting 
the resulting positive secondary ions. The depth scale of the SIMS craters was determined by employing a Dektak XT stylus surface profilometer [29]. As shown in Fig. 4, for a sample obtained by using ALD (i.e., the $\mathrm{TiO}_{2}$ film shown in Fig. 4(a)) and a sample obtained by employing PLD (i.e., the $\mathrm{MoS}_{2}$ film shown in Fig. 4(b)), the obtained results confirmed that the elemental distribution of the thin-film constituents along their depths is quite constant, revealing once more their good homogeneity. In addition, these results allowed establishing that the thicknesses of the thin films used were $20 \mathrm{~nm}$ for $\mathrm{Al}_{2} \mathrm{O}_{3}, 50 \mathrm{~nm}$ for $\mathrm{TiO}_{2}$, $100 \mathrm{~nm}$ for $\mathrm{Al}$ and $65 \mathrm{~nm}$ for $\mathrm{MoS}_{2}$, while it was also shown that the respective constituents permeate the Si substrate deeper.

\section{Calibration of the probes}

To tune the measurement conditions and quantify the obtained results, a precise calibration of the probes, and specifically of their bending and torsional stiffness, is needed. In the contact-mode measurements used, these are the main parameters determining the correlation factor linking the friction force $F_{\mathrm{f}}$ to the SPM voltages resulting from the LFM measurements. The probes used were Bruker's SNL-10 high-resolution probes, type $\mathrm{D}$ for the smaller $F_{\mathrm{N}}$ values considered, and type A for the larger $F_{\mathrm{N}}$ values considered, both with a $\mathrm{Si}$ tip mounted on a triangular $\mathrm{Si}_{3} \mathrm{~N}_{4}$ cantilever [30]. By using the conventional AFM ramping curve on a hard sapphire sample, the normal deflection sensitivity of the probes was thus determined to be $98.3 \pm 5.1 \mathrm{~nm} / \mathrm{V}$.

The validation of the bending stiffness $k_{\mathrm{b}}$ of the microcantilevers with respect to its nominal value $(0.06 \mathrm{~N} / \mathrm{m})$ was performed via the thermal tune method (TTM), i.e., by measuring the power spectral density of the cantilevers' motion in the time-domain in response to dynamic excitations [31]. The results reported in Table 2 for the SNL-10D probes [32] were used to validate the calculations of $k_{\mathrm{b}}$ performed by using the analytical method of parallel beam approximations (PBA) [33], as well as via finite element modelling (FEM) performed in Ansys ${ }^{\circledR}$. The calculations were in turn, based on an accurate characterization of the geometry of the probes (Fig. 5(a)) via measurements using a Jeol JSM-7800F scanning electron microscopy (SEM) device available again at the NANORI premises [17], which allows magnifications up to 1,000,000 times and imaging resolutions down to $0.8 \mathrm{~nm}$ (Fig. 5(b)) [16].

Ten probe samples were scanned using the SEM device in order to obtain statistics on the dispersion of their dimensions due to the production process (Table 3). Respective calculations were then conducted taking into account 25 permutations of variable normal and transverse loads in the range of 10 to $100 \mathrm{nN}$. A sensitivity analysis of the FEM results, i.e., a study of the influence of the geometric parameters on the transverse deformation of the probes, showed that, as expected, the thickness of the probes has the highest influence on the resulting deformations. The obtained values of the flexural and, subsequently, of the torsional stiffness $k_{\mathrm{t}}$ are reported in Table 2. It should be noted
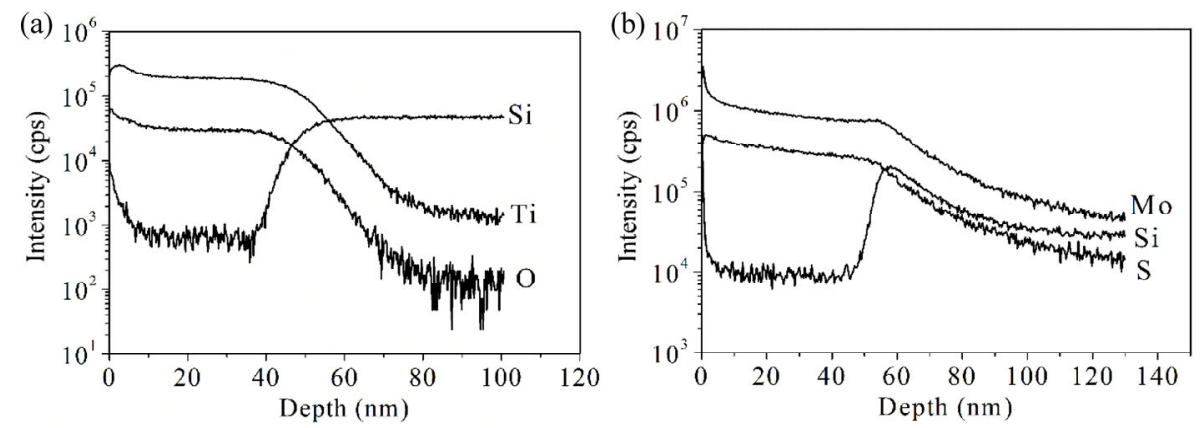

Fig. 4 SIMS spectra for $\mathrm{TiO}_{2}$ obtained via $\operatorname{ALD}(\mathrm{a})$, and $\mathrm{MoS}_{2}$ obtained by using PLD (b).

Table 2 Determined bending and torsional stiffness of the Bruker SNL-10D probes.

\begin{tabular}{cccc}
\hline & TTM & PBA & FE \\
\hline$k_{\mathrm{b}}\left(\mathrm{N} \cdot \mathrm{m}^{-1}\right)$ & $0.086 \pm 17 \%$ & $0.056 \pm 12 \%$ & $0.098 \pm 8 \%$ \\
$k_{\mathrm{t}}\left(\mathrm{N} \cdot \mathrm{m} \cdot \mathrm{rad}^{-1}\right)$ & & $79.37 \pm 16 \%$ & $92.59 \pm 11 \%$ \\
\hline
\end{tabular}



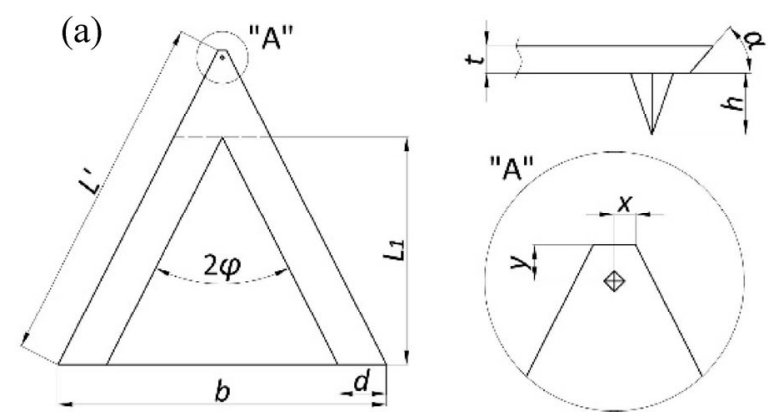

(b)

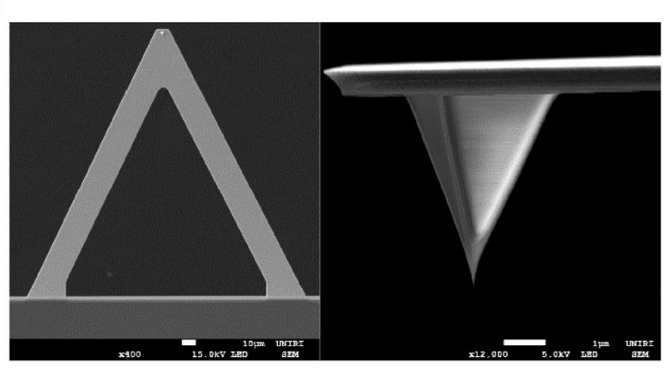

Fig. 5 Geometrical parameters of the used Bruker SNL-10 probes (a) and SEM micrographs of the planar and side view of the probes (b).

Table 3 Measured dimensions of the Bruker SNL-10D SPM probes.

\begin{tabular}{ccc}
\hline & Average & Std. dev. $\pm \sigma$ \\
\hline$L^{\prime}(\mu \mathrm{m})$ & 214.17 & 0.77 \\
$L_{1}(\mu \mathrm{m})$ & 150.58 & 0.50 \\
$d(\mu \mathrm{m})$ & 22.90 & 0.51 \\
$b(\mu \mathrm{m})$ & 201.59 & 1.10 \\
$\varphi\left(^{\circ}\right)$ & 26.25 & 0.81 \\
$\alpha\left(^{\circ}\right)$ & 60.29 & 5.46 \\
$t(\mu \mathrm{m})$ & 0.55 & 0.03 \\
$h(\mu \mathrm{m})$ & 4.71 & 0.14 \\
$x(\mu \mathrm{m})$ & 5.08 & 0.17 \\
$y(\mu \mathrm{m})$ & 3.58 & 0.11 \\
\hline
\end{tabular}

that the uncertainty of the values of the dimensions has a marked (up to roughly $\pm 15 \%$ ) influence on the determined stiffness values.

With respect to the flexural stiffness $k_{\mathrm{b}}$, it should also be noted that, since temperature was considered as one of the studied influencing parameters, the rise of the temperature of the set-up induces thermal dilatations of the samples [34], of the piezoelectric actuators used to move the probes, and of the probes themselves (Fig. 6). These thermal effects induce a necessity to change the set-point, i.e., to vary the necessary elongation of the vertical actuator needed to maintain a determined (required) value of the normal force (in order to maintain a constant flexural deflection reading on the photodetector of the SPM device during the LFM measurements) [34]. Based on a thorough study of this issue, it was thus determined that for lower temperature values the set-points are positive, they have a tendency towards 0 at temperatures of roughly $40{ }^{\circ} \mathrm{C}$, while for higher temperatures they tend to assume negative values. These variations were thus considered in setting-up each measurement.

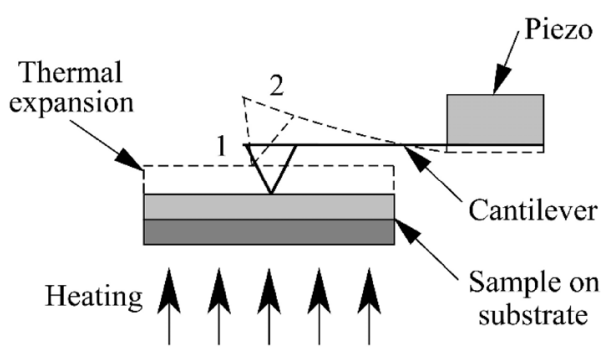

Fig. 6 Influence of thermal expansion on the normal force $F_{\mathrm{N}}$, i.e., on the necessity to correct the set-point.

The determination of the factor correlating the lateral voltage signal on the SPM photodetector (cf. Fig. 1) to forces related to the torsional stiffness $k_{\mathrm{t}}$, i.e., to forces inducing the probes' torsion, was conducted by employing calibrated TGF11 arrays of trapezoidal gratings in a monocrystalline Si substrate along the (111) crystallographic planes [35]. By considering the resulting force and torque equilibria, as explained in Ref. [36], as well as the torsional stiffness of the probes attained via the FEM calculations and the dimensions of the probes determined via the SEM measurements, a relationship between the torsion of the probe, as measured on the SPM photodetector, and the friction force $F_{\mathrm{f}}$ was finally obtained. For the considered $F_{\mathrm{N}}$ range at a constant temperature of $21{ }^{\circ} \mathrm{C}$, in the considered case the described procedure on the TGF11 sample allowed hence determining that for the Bruker SNL-10D probes the correlation factor linking $F_{\mathrm{f}}$ to the SPM voltages, resulting from the LFM measurements, is $0.035 \mu \mathrm{N} / \mathrm{V}$.

The importance of the surface adhesive forces at the nanoscale cannot be overstated in this frame. In addition, especially in technologically recurring in-air environments, adhesion depends a lot on the state of the surface layer, which changes with temperature [1]. Therefore, a thorough study of the dependence of the 
adhesive force $F_{\mathrm{A}}$ on the temperature of the TGF11 grating was performed. $F_{\mathrm{A}}$ values were attained from conventionally used force vs. tip distance curves by using the aforementioned PF-QNM measurement mode. The retraction of the tip from the sample with the consequent reaching of the point when the pull-out force becomes larger than adhesion, and the probes' cantilever springs back to zero-force deflection, allows thus the adhesive forces $F_{\mathrm{A}}$ to be effectively quantified. It is important to note here especially that the total force acting on the sample is the sum of $F_{\mathrm{N}}$ and $F_{\mathrm{A}}$; the relevance of this fact will be thoroughly addressed in Section 6 of this paper.

The obtained results allow a marked variation of $F_{\mathrm{A}}$ with temperature (Fig. 7(a)) to be established. The change of the respective correlation factor in the determined 50 sample points results in a range of values from $0.0068 \mu \mathrm{N} / \mathrm{V}$ up to $0.071 \mu \mathrm{N} / \mathrm{V}$, i.e., a variation of a whole order of magnitude. The variation of $F_{\mathrm{A}}$ was monitored on the thin-film samples by again employing the PF-QNM measurement mode, and its dependence on temperature is shown in Fig. 7(b). A strong dependence can thus be observed once more, but it can also be seen that for all the samples the global trends are very similar: a marked peak of $F_{\mathrm{A}}$ at around $30{ }^{\circ} \mathrm{C}$ is present with a subsequent sharp decrease in the $F_{\mathrm{A}}$ values for temperatures approaching $40{ }^{\circ} \mathrm{C}$. The complex physio-chemical interactions behind these observed trends are being thoroughly investigated in a separate study via molecular modelling calculations being performed at the Molecular Simulations Engineering (MOSE) laboratory of the University of Trieste, Italy [37].

The calibration of the flexural and torsional stiffnesses of the probes, and that of the respective correlation factors for determining the friction force from the measured LFM voltage signals, were thus successfully accomplished, and this allowed quantitative measurements of the frictional forces $F_{\mathrm{f}}$ to be performed.

\section{Tip wear and adhesion}

As an unwanted result of nanoscale wear due to asperity contacts and atomic attrition between the probes and the samples, the geometry at the apex of the probes' tips changes $[1,38,39]$. The change in the tip's radius influences the adhesive force between the tip and the surface of the samples [40-42]. Adhesion also depends on air humidity [25, 41], which was monitored and controlled during the measurements. The average obtained value of the relative humidity was $50 \% \pm 1 \%$ and that of air temperature was $21 \pm 0.1{ }^{\circ} \mathrm{C}$. The determined sample temperature values (variable across the set of experiments but constant in each of them) were maintained long enough to achieve stable experimental conditions and kept stable by employing the Bruker Thermal Applications Controller (TAC).

Tip wear was thus a very important parameter in attaining accurate friction force measurements. Generally, the geometry of the probes' tips can be determined by using methods that involve the manufacturer's specifications, SEM or other imaging techniques, and/or by employing tip SPM scans on specially devised tip characterizing samples coupled to deconvolution algorithms $[43,44]$.

The nominal specifications that the manufacturers provide in terms of tip geometry, have to be taken with a degree of caution because of the variability in the production batches (cf. Table 3), and because tip wear has to be considered as well. In this study the methods of using SEM images and tip characterization samples were thus adopted. SEM micrographs of a
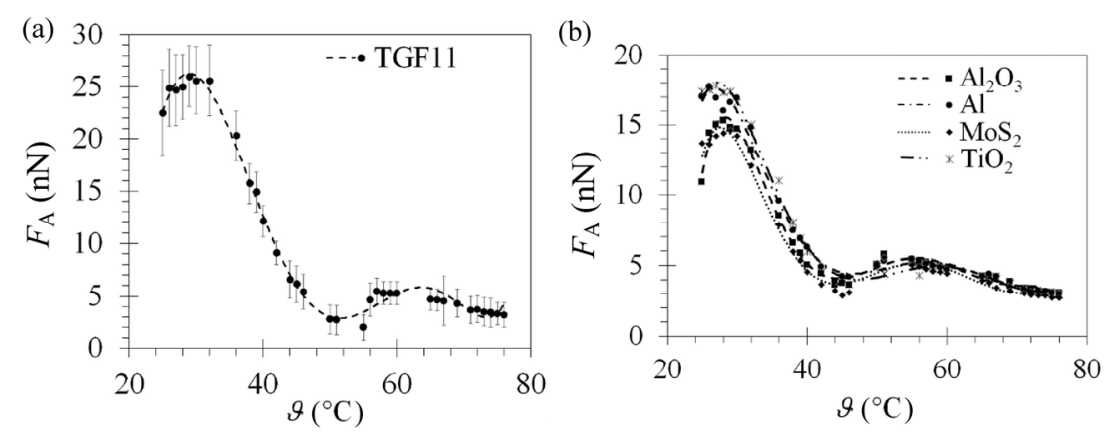

Fig. 7 Dependence of $F_{\mathrm{A}}$ on temperature for the TGF11 calibration grating (a), and for the considered thin-film samples (b). 
new tip apex and of the same tip after more than 200 LFM scans, obtained again by using the FE-SEM Jeol JSM-7800F device at the NANORI premises [16, 17], are hence shown in Fig. 8, clearly showing the marked wear of the tip. The SEM images were used next to measure the radius $r$ of the tip's apex by best-fitting a circle through the image of the tip. In the particular example shown in Fig. 8, the radii obtained of the new and worn tips were 32 and $95 \mathrm{~nm}$, respectively.

Estimation algorithms for reconstructing the tip geometry were subsequently implemented in the MATLAB $^{\circledR}$ software environment. In fact, based on SPM scans on a standard Bruker's titanium characterizing sample [44], whose surface is specifically adapted to the aim of deducing the tip conditions, the so-called "tip evaluation" tool in the Nanoscope software, coupled to an in-house developed MATLAB code, generated a model of the tip. In the tip evaluation tool, the local peaks in a topographic image, and the respective slopes in all directions, were successively analyzed, refining the three-dimensional (3D) tip model-thus allowing to deduce the minimal tip sharpness. In addition, this tool allowed attaining an estimate of the tip's maximum cross-sectional width at two distinct distances (ETD 1 and ETD 2) from its apex. The value of the "aspect ratio" was defined as the ratio of the major and minor semi-axes of the tip's cross section, and it was obtained at ETD 1 and ETD 2 (Table 4).

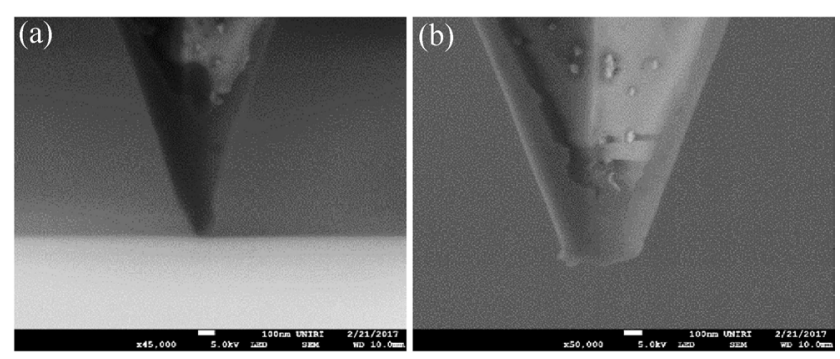

Fig. 8 SEM micrographs of a fresh (a) and of an SPM tip used for 200 LFM measurements (b).

Table 4 Results of the determination of tip's apex radius.

\begin{tabular}{lcc}
\hline \multicolumn{1}{c}{ Parameter } & Fresh tip & Worn tip \\
\hline ETD 1 & $31.9 \mathrm{~nm}$ & $54.1 \mathrm{~nm}$ \\
ETD 1, aspect ratio & 0.91 & 0.67 \\
ETD 2 & $72.9 \mathrm{~nm}$ & $138.8 \mathrm{~nm}$ \\
ETD 2, aspect ratio & 0.76 & 1.00 \\
$d_{\text {est }}$ & $28.0 \mathrm{~nm}$ & $75.8 \mathrm{~nm}$ \\
\hline
\end{tabular}

By inputting this data into the MATLAB deconvolution algorithm, the estimated truncated coneshaped geometry of the probe was obtained. From this, the probe's major tip axis at section ETD 1 in the vicinity of the probe's apex was found. The estimated dimension $d_{\text {est }}$ of the virginal tip's apex was therefore approximated with a value of $28.0 \mathrm{~nm}$, whereas that of the worn tip increased to $75.8 \mathrm{~nm}$ (Table 4).

Measurements of the dependence of adhesion on wear were hence conducted. These were performed by using a fresh tip on an $\mathrm{Al}_{2} \mathrm{O}_{3}$ sample that has high abrasive properties. Contact-mode scans on a $500 \mathrm{~nm} \times$ $500 \mathrm{~nm}$ surface, with 512 scan lines (i.e., double with respect to those used in the actual LFM measurements), were performed at the maximum considered scan speed of $v=500 \mathrm{~nm} / \mathrm{s}$, while maintaining $\vartheta=20^{\circ} \mathrm{C}$; $256,000 \mathrm{~nm}$ were thus covered in a single scan. A total of 100 scans were then made so that the aggregate scan distance was $25.6 \mathrm{~mm}$. Figure 9 shows the resulting values of the estimated major tip axis $d_{\text {est }}$ and of the adhesive forces $F_{\mathrm{A}}$. The latter were attained from the conventionally used force vs. tip distance curves. The previously mentioned spring-back of the cantilever to zero-force deflection, allows the dependence of $F_{\mathrm{A}}$ to be quantified for different degrees of wear of the tip. The values of adhesion will, obviously, increase with increasing tip wear, i.e., at a constant $d_{\text {scan }}$ value, adhesion will grow for increasing applied normal loads $F_{\mathrm{N}}$. Figure 9 thus shows the $F_{\mathrm{A}}$ and $d_{\text {est }}$ vs. $d_{\text {scan }}$ curves for the maximum $F_{\mathrm{N}}$ value considered, $F_{\mathrm{N}}=$ $150 \mathrm{nN}$. In this worst case, in terms of the resulting effect of adhesion on the uncertainty of the measurements, roughly 200 LFM measurements with 256 scan lines performed for each of them would have a comparable effect to that of the uncertainty introduced by the dispersion of the stiffness of the probes, as determined in Section 4. For this reason, bearing in mind the necessity to have reliable measurements, but at the same time also the need to minimize the usage of fresh tips and the respective costs, a sufficiently large safety margin was introduced. A new tip was thus used in the measurements of the friction force $F_{\mathrm{f}}$ for no more than 50 LFM measurements cycles; this corresponds to a travel distance limited to $6 \mathrm{~mm}$, which induces a change of $F_{\mathrm{A}}$ limited to $1.5 \mathrm{nN}(1 \%$ of the used $F_{\mathrm{N}}$ value-cf. Fig. 9). The introduced variability of the applied force was thus also limited to roughly 


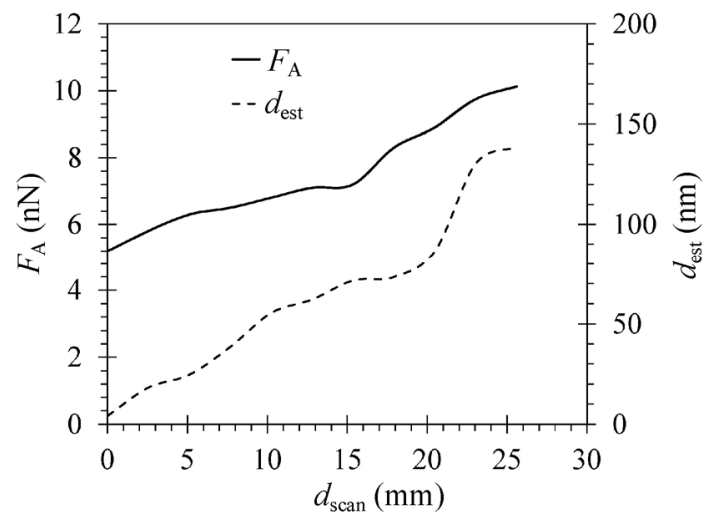

Fig. 9 Wear of a tip on an $\mathrm{Al}_{2} \mathrm{O}_{3}$ surface for $F_{\mathrm{N}}=150 \mathrm{nN}$ : resulting adhesion (left axis) and tip dimension (right axis).

$1 \%$, i.e., it was markedly smaller than the uncertainty introduced by the variability of the stiffness of the used probes. This important conclusion allows the accuracy of the subsequently performed $F_{\mathrm{f}}$ measurements to be enhanced. On the other hand, the increase of $d_{\text {est }}$ induces a corresponding increase of the contact area. According to the friction model of Bowden and Tabor [1, 13], this increase is directly related to the value of the friction force. However, in the considered cases the value of the used normal forces $F_{\mathrm{N}}$ is small, i.e., in the $\mathrm{nN}$ range, so no plastic deformation is expected even for the largest $F_{\mathrm{N}}$ values as those considered in Fig. 9. In addition, even in this extreme case, the contact pressure value is an order of magnitude lower than the yield stress of alumina [45]. In fact, conventional topological SPM contact-mode measurement scans performed after the friction measurement did not reveal any wear of the surfaces of the samples. The influence of increasing contact areas on adhesion was, in turn, in any case considered in its repercussions on the adhesive forces $F_{\mathrm{A}}$.

\section{Results of the measurements of the friction force $F_{\mathrm{f}}$}

All of the above procedures allow the actual SPM measurements on the prepared samples to be performed next. Preliminary measurements were made with the conventional SPM contact-mode measurement configuration, i.e., by measuring the topography of the samples. From the obtained results, reported in Table 5, it is evident that the samples are characterized by small values of the arithmetic average surface
Table 5 Surface roughness parameters of the analysed samples.

\begin{tabular}{ccccccc}
\hline & $\begin{array}{c}R_{\mathrm{a}} \\
(\mathrm{nm})\end{array}$ & $\begin{array}{c}\text { St. dev. } \pm \\
\sigma(\mathrm{nm})\end{array}$ & $\begin{array}{c}R_{\mathrm{q}} \\
(\mathrm{nm})\end{array}$ & $\begin{array}{c}\text { St. dev. } \pm \\
\sigma(\mathrm{nm})\end{array}$ & $\begin{array}{c}R_{\mathrm{Z}} \\
(\mathrm{nm})\end{array}$ & $\begin{array}{c}\text { St. dev. } \pm \\
\sigma(\mathrm{nm})\end{array}$ \\
\hline $\mathrm{MoS}_{2}$ & 8.04 & 1,3 & 10.18 & 1.8 & 15.0 & 2.3 \\
$\mathrm{Al}_{2} \mathrm{O}_{3}$ & 12.4 & 2.6 & 14.6 & 2.9 & 16.05 & 3.2 \\
$\mathrm{TiO}_{2}$ & 6.3 & 1.7 & 8.8 & 2.3 & 9.8 & 2.8 \\
$\mathrm{Al}$ & 4.2 & 1.35 & 7.1 & 2.45 & 7.9 & 2.3 \\
\hline
\end{tabular}

roughness $R_{a}$ the RMS roughness $R_{\mathrm{q}}$ and the maximum height $R_{Z}$. It is also evident that the dispersion of these values in the performed repetitive measurements is rather small.

LFM measurements were then conducted with the aim of attaining data relative to the friction forces $F_{\mathrm{f}}$ and their variation in the multidimensional space given by the considered influencing parameters and their ranges of variation. Figure 10 thus depicts the $F_{\mathrm{f}}$ values obtained for the considered thin-film samples at the measurement points attained by employing the described CVT-based DoE methodology (cf. again Appendix 1); the points in the figure represent the mean $F_{\mathrm{f}}$ values in repetitive measurements, scaled according to the color-coding shown in the legend.

In the left part of Fig. 10 are depicted the conventional values of $F_{\mathrm{f}}$ generally reported in the literature, i.e., those when the average correlation factor linking $F_{\mathrm{f}}$ to the SPM voltages, resulting from the LFM measurements and neglecting the variation of $F_{\mathrm{A}}$ with temperature, is considered. In the right part of Fig. 10 are depicted the dependencies of $F_{\mathrm{f}}$ on the considered influencing parameters when the true total force acting on the samples (i.e., $F_{\mathrm{N}}+F_{\mathrm{A}}$ ), that influences the torsion on the probes, is considered. In this case, the $F_{\mathrm{f}}$ values shown for each sample point account also for the $F_{\mathrm{A}}$ vs. $\vartheta$ variation, i.e., the variability of the correlation factors as determined in Section 4.

From the values reported in Fig. 10, it can be inferred that the scatter of the obtained $F_{\mathrm{f}}$ values, attained by considering a constant $\mu \mathrm{N} / \mathrm{V}$ LFM correlation factor, does not allow the real peculiarities of the physical dependence of nanometric friction on its main influencing parameters to be appreciated, resulting in a poor overall appreciation of the real correlations among these values. In addition, it would seem that, in general, in this case $F_{\mathrm{f}}$ is largest for the highest considered temperatures. When, however, the influence 

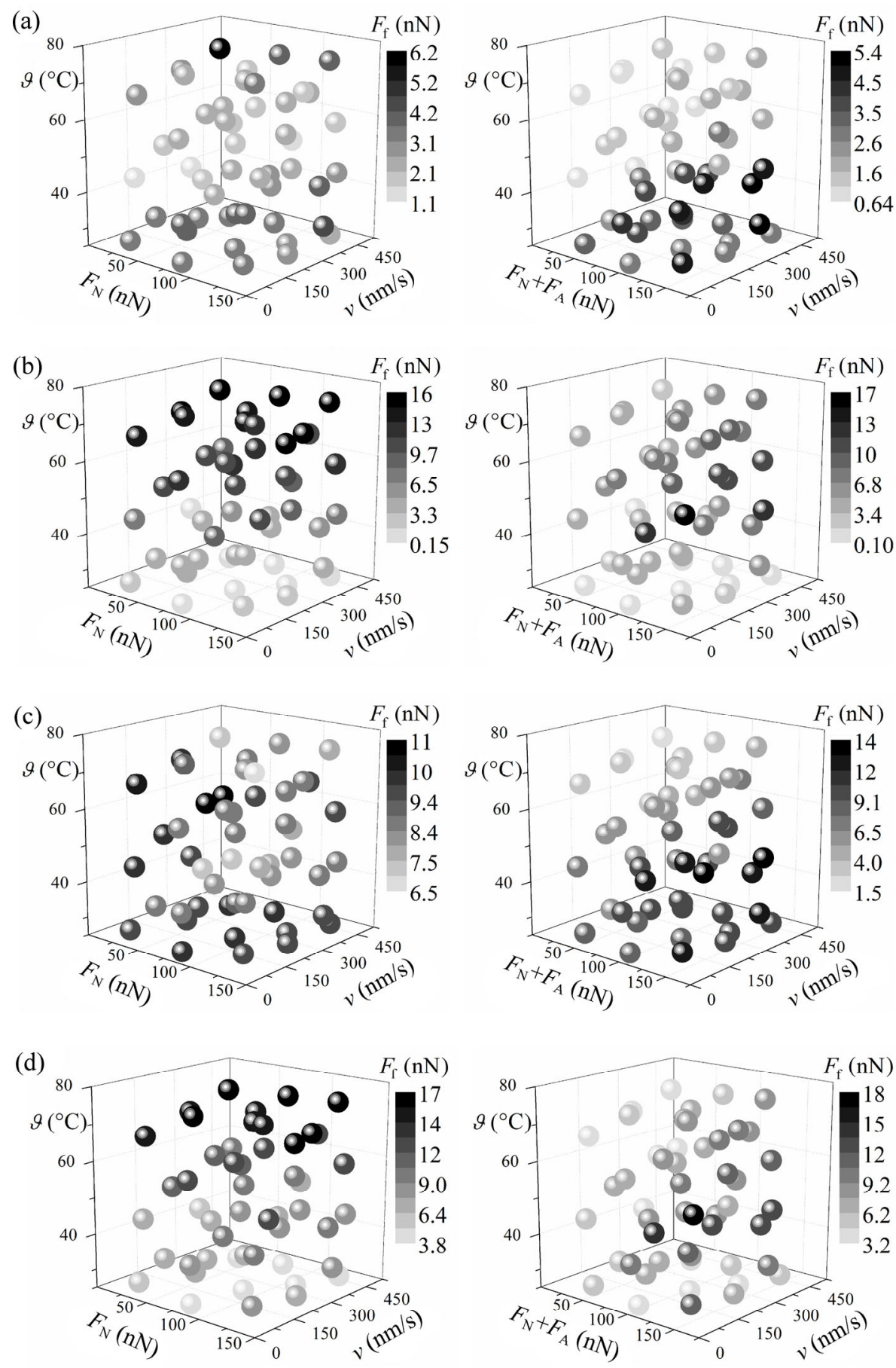

Fig. 10 Colour-coded distribution of experimentally determined nanometric $F_{\mathrm{f}}$ values on 50 measurement points for the $\mathrm{Al}_{2} \mathrm{O}_{3}$ (a), $\mathrm{TiO}_{2}$ (b), $\mathrm{Al}(\mathrm{c})$ and $\mathrm{MoS}_{2}$ (d) samples vs. the respective influencing parameters.

of the variability of $F_{\mathrm{A}}$ on $\vartheta$ and the resulting change of the correlation factor is taken into account, the similitude of the $F_{\mathrm{f}}$ value trends and of the dependence of nanoscale friction on the studied parameters for all the considered thin films becomes much clearer. In this case, the highest $F_{\mathrm{f}}$ values start clustering at temperatures $\vartheta$ of around $40{ }^{\circ} \mathrm{C}$, for the highest considered applied loads $F_{\mathrm{N}}+F_{\mathrm{A}}$ and, tendentially, for lower to mid-range considered velocities $v$.

It should be noted that in all considered cases the depicted mean $F_{\mathrm{f}}$ values were characterized by a high stochastic dispersion (up to $\pm 10 \%$ ) that, considering 
the number of influencing parameters, complicates the development of a mathematical model that would allow the influencing parameters to be correlated to the respective $F_{\mathrm{f}}$ values. In fact, polynomial fitting of the obtained results via the often-used multidimensional interpolation algorithms yields a poor fit with the best coefficients of determination limited to about $R^{2}=0.1$.

To gain a far better appreciation and insight into the sensitivity of the $F_{\mathrm{f}}$ values on the considered influencing parameters, a statistical analysis was used as a benchmark and as guidelines for the subsequently planned advanced analyses. Correlation matrices, obtained by using Pearson's product-moment correlation (PPMC) [46] on the large set of acquired $F_{\mathrm{f}}$ data, are thus summarized in Table 6 . Here, a correlation coefficient of 1 or -1 shows a perfect (linear) correlation

Table 6 Matrices of correlation coefficients for the influencing parameters on the $F_{\mathrm{f}}$ values for the $\mathrm{Al}_{2} \mathrm{O}_{3}, \mathrm{TiO}_{2}, \mathrm{Al}$ and $\mathrm{MoS}_{2}$ samples when the tip-exerted normal force $\left(F_{\mathrm{N}}\right)$ and the true total force acting on the samples $\left(F_{\mathrm{N}}+F_{\mathrm{A}}\right)$ are considered.

\begin{tabular}{|c|c|c|c|c|c|c|c|}
\hline & & $v$ & $F_{\mathrm{N}}$ & $\vartheta$ & $F_{\mathrm{f}}$ & $F_{\mathrm{A}}$ & $F_{\mathrm{N}}+F_{\mathrm{A}}$ \\
\hline \multirow{6}{*}{$\mathrm{Al}_{2} \mathrm{O}_{3}$} & $v$ & 1 & & & & & \\
\hline & $F_{\mathrm{N}}$ & 0.032 & 1 & & & & \\
\hline & $\vartheta$ & 0.028 & 0.079 & 1 & & & \\
\hline & $F_{\mathrm{f}}$ & 0.0023 & 0.382 & -0.64 & 1 & & \\
\hline & $F_{\mathrm{A}}$ & -0.068 & -0.035 & -0.835 & 0.483 & 1 & \\
\hline & $F_{\mathrm{N}}+F_{\mathrm{A}}$ & 0.025 & 1 & -0.015 & 0.436 & 1 & 1 \\
\hline \multirow{6}{*}{$\mathrm{TiO}_{2}$} & $v$ & 1 & & & & & \\
\hline & $F_{\mathrm{N}}$ & 0.032 & 1 & & & & \\
\hline & $\vartheta$ & 0.028 & 0.079 & 1 & & & \\
\hline & $F_{\mathrm{f}}$ & 0.014 & 0.48 & 0.47 & 1 & & \\
\hline & $F_{\mathrm{A}}$ & -0.068 & -0.046 & -0.85 & -0.62 & 1 & \\
\hline & $F_{\mathrm{N}}+F_{\mathrm{A}}$ & 0.022 & 1 & -0.048 & 0.386 & I & 1 \\
\hline \multirow{6}{*}{$\mathrm{Al}$} & $v$ & 1 & & & & & \\
\hline & $F_{\mathrm{N}}$ & 0.032 & 1 & & & & \\
\hline & $\vartheta$ & 0.028 & 0.079 & 1 & & & \\
\hline & $F_{\mathrm{f}}$ & 0.014 & 0.399 & -0.71 & 1 & & \\
\hline & $F_{\mathrm{A}}$ & -0.053 & -0.05 & -0.86 & 0.442 & 1 & \\
\hline & $F_{\mathrm{N}}+F_{\mathrm{A}}$ & 0.025 & 1 & -0.043 & 0.460 & 1 & 1 \\
\hline \multirow{6}{*}{$\mathrm{MoS}_{2}$} & $v$ & 1 & & & & & \\
\hline & $F_{\mathrm{N}}$ & 0.032 & 1 & & & & \\
\hline & $\vartheta$ & 0.028 & 0.079 & 1 & & & \\
\hline & $F_{\mathrm{f}}$ & -0.056 & 0.625 & 0.061 & 1 & & \\
\hline & $F_{\mathrm{A}}$ & -0.071 & -0.056 & -0.84 & -0.27 & 1 & \\
\hline & $F_{\mathrm{N}}+F_{\mathrm{A}}$ & 0.024 & l & -0.017 & 0.594 & / & 1 \\
\hline
\end{tabular}

of positive (proportional) or negative (inversely proportional) dependence, respectively, on the considered influencing parameter, with higher absolute values indicating a stronger dependence, while a zero (or near-zero) value indicates that there is no correlation.

In Table 6, both the correlation that considers the exerted normal force $F_{\mathrm{N}}$ alone, as well as that which considers the total force $F_{\mathrm{N}}+F_{\mathrm{A}}$ acting on the samples, in both cases with adhesion-corrected calibration factors, are shown. It can thus be inferred that, for all the considered thin-film materials, the influence of $F_{\mathrm{N}}$ on the nanoscale friction force $F_{\mathrm{f}}$ has a positive correlation in the range from ca. 0.4 for $\mathrm{Al}$ and $\mathrm{Al}_{2} \mathrm{O}_{3}$, ca. 0.5 for $\mathrm{TiO}_{2}$ and ca. 0.6 for the $\mathrm{MoS}_{2}$ samples. When the total force $F_{\mathrm{N}}+F_{\mathrm{A}}$ acting on the samples is considered, the respective correlation coefficients change, however, to roughly 0.45 for $\mathrm{Al}$ and $\mathrm{Al}_{2} \mathrm{O}_{3}$, 0.4 for $\mathrm{TiO}_{2}$ and 0.6 for $\mathrm{MoS}_{2}$. Although the general trend observed in relation to Fig. 10 is thus confirmed, i.e., $F_{\mathrm{f}}$ clearly rises with increasing $F_{\mathrm{N}}+F_{\mathrm{A}}$ values, it is interesting to note especially the peculiar effect of the adhesion force $F_{\mathrm{A}}$ for the different considered sample materials. In fact (cf. the respective rows related to $F_{\mathrm{A}}$ in Table 6), for the $\mathrm{Al}$ and $\mathrm{Al}_{2} \mathrm{O}_{3}$ samples, $F_{\mathrm{A}}$ has a relatively high positive influence on $F_{\mathrm{f}}$, i.e., a rise of $F_{\mathrm{A}}$ induces an increase of the total contact load and hence a rise of the friction force $F_{\mathrm{f}}$. On the other hand, however, in the case of the $\mathrm{TiO}_{2}$ and $\mathrm{MoS}_{2}$ samples, there is a negative influence of $F_{\mathrm{A}}$ on $F_{\mathrm{f}}$, with correlation factors of -0.62 and -0.27 , respectively, which implies diminishing $F_{\mathrm{f}}$ values for increasing $F_{\mathrm{A}}$ values. This fact not only confirms once more the postulated complex nature of adhesion, induced by multivariate phenomena due to atomic interactions and surface energies, but it could also, perhaps, indicate an occurrence of a possible lubricating effect on the surfaces of the $\mathrm{TiO}_{2}$ and $\mathrm{MoS}_{2}$ samples that induces the observed partial decrease of $F_{\mathrm{f}}$ with increasing $F_{\mathrm{A}}$ values. In any case it seems that, for the nanoscale contact of the Si tip with the $\mathrm{TiO}_{2}$ and $\mathrm{MoS}_{2}$ samples, adhesion manifests itself as a lubricating effect. In addition, as extensively elaborated above, adhesion is also closely related to temperature. When in Table 6 the correlation of nanoscale friction $F_{\mathrm{f}}$ with temperature $\vartheta$ is observed, relatively high negative correlation values of -0.71 and -0.64 are attained for the $\mathrm{Al}$ and $\mathrm{Al}_{2} \mathrm{O}_{3}$ samples, respectively, i.e., once more a physio-chemical similitude 
of these films is confirmed, which, in this case, results in a decrease of $F_{\mathrm{f}}$ for rising temperatures. Referring to Fig. 10(b), this would also imply that a rising temperature prompts a relative decrease of $F_{\mathrm{A}}$ (i.e., of the respective total load $F_{\mathrm{N}}+F_{\mathrm{A}}$ acting on the samples), thus causing the lowering of its influence on $F_{\mathrm{f}}$ as well. In the case of the $\mathrm{TiO}_{2}$ sample, however, a positive $(0.47)$ correlation between $F_{\mathrm{f}}$ and $\vartheta$ is obtained instead. This could be due to exactly the opposite effect with respect to that hypothesized for $\mathrm{Al}$ and $\mathrm{Al}_{2} \mathrm{O}_{3}$, i.e., that in this case the rise of $\vartheta$, inducing a relative decrease of $F_{\mathrm{A}}$ (cf. Fig. 10(b)), combined with the earlierdiscussed negative correlation of $F_{\mathrm{A}}$ on $F_{\mathrm{f}}$, induces a resulting increase of $F_{\mathrm{f}}$ (i.e., a decrease of the favorable lubricating effect). Finally, the $\mathrm{MoS}_{2}$ sample shows a negligible (0.06) correlation between $F_{\mathrm{f}}$ and temperature $\vartheta$.

When, referring once more to Table 6 , the influence of sliding velocity $v$ on nanoscale friction $F_{\mathrm{f}}$ is considered, it becomes evident that, for all the considered thin films and contrary to the known effects on the macro- and mesoscales, at the nanoscale and in the considered velocity regime there is only a negligible correlation of $F_{\mathrm{f}}$ with $v$, with the respective correlation coefficients being in the $10^{-3}$ to $10^{-2}$ range. Since in recent literature $[47,48]$ it has been reported that at the nanoscale the influence of $v$ on $F_{\mathrm{f}}$ is highly dependent on the magnitude of sliding velocity, it is evident that, similar to what was established in a much broader velocity range in Ref. [13], in the considered velocity range (up to $500 \mathrm{~nm} / \mathrm{s}$ ), the effect of $v$ on $F_{\mathrm{f}}$, especially when related to the effects induced by the other considered influencing parameters (variable loads $\left(F_{\mathrm{N}}\right.$ or $\left.F_{\mathrm{N}}+F_{\mathrm{A}}\right)$ or temperatures $\left.\vartheta\right)$, is indeed negligible.

All the considered effects are summarized for convenience and an easier overview in Table 7, where for all the analyzed samples the trends of the effects of all the studied influencing parameters on the value of the nanoscale friction force $F_{\mathrm{f}}$ are given, allowing a much better appreciation of the fundamental trends. The + and - signs indicate an increase or a decrease, respectively, of the $F_{\mathrm{f}}$ values depending on the variation of the corresponding influencing parameter, while a " 0 " sign indicates no meaningful correlation. The value of the respective correlation factor is, in turn,
Table 7 Summary of the effects of the influencing parameters on the value of nanoscale friction $F_{\mathrm{f}}$ for the used thin-film samples.

\begin{tabular}{cccccc}
\hline & $F_{\mathrm{N}}$ & $F_{\mathrm{A}}$ & $F_{\mathrm{N}}+F_{\mathrm{A}}$ & $v$ & $\vartheta$ \\
\hline \multirow{2}{*}{$\mathrm{Al}_{2} \mathrm{O}_{3}$} & + & + & + & 0 & - \\
& $(0.38)$ & $(0.48)$ & $(0.43)$ & $(0.002)$ & $(-0.64)$ \\
$\mathrm{TiO}_{2}$ & + & - & + & 0 & + \\
& $(0.48)$ & $(-0.62)$ & $(0.39)$ & $(0.014)$ & $(0.47)$ \\
$\mathrm{Al}$ & + & + & + & 0 & - \\
& $(0.40)$ & $(0.44)$ & $(0.46)$ & $(0.014)$ & $(-0.71)$ \\
$\mathrm{MoS}_{2}$ & + & - & + & 0 & 0 \\
& $(0.63)$ & $(-0.27)$ & $(0.59)$ & $(-0.056)$ & $(0.061)$ \\
\hline
\end{tabular}

shown in parentheses. However, as stated above, these correlations are just first-order linear statistical approximations of the generalized trends of the influence of the studied dependence of nanoscale friction in the multidimensional space defined by the considered process parameters. A more elaborate analysis tool is needed to determine the complete set of correlation factors that would allow the respective functional dependencies to be established.

\section{Conclusions and outlook}

A thorough description of a structured methodology for the experimental determination of nanometric friction performed under the concurrent influence of several influencing parameters is provided in this paper. An advanced approach to the design of experimental measurements is suggested and successfully implemented. The numerous issues involved in this challenging task were systematically studied: the synthesis and characterization of the samples, the importance of the calibration of the probes and the importance of the variability of adhesion on this calibration, as well as the importance of wear and adhesion of the probes themselves.

The results of the developed systematic approach provide important insights into the general trends of the dependence of nanoscale friction on the multiple process parameters, as well as an indication of the respective correlations. An intricate concurrent dependence of nanoscale friction on the variable parameters was thus obtained, confirming the assumption that their interactions and mutual effects must be investigated at the structural atomic level to be fully appreciated. To this end, an examination of the possibility of comparing the obtained experimental 
results to molecular modelling calculations performed at the MOSE laboratory of the University of Trieste, Italy [37] is under way.

The full potential of the proposed methodology will be enhanced in the next phase of this work when the obtained experimental data are input into the recently developed elaborate mathematical procedure based on algorithms for nonlinear model representation that enable a simultaneous examination of global uncertainties and contributions of a large number of parameters [23]. This study should allow correlation function(s) linking the considered process variables to the value of nanometric friction to be finally obtained, thus providing not only an even deeper insight into the studied phenomena due to complex interactions, but also eventually allowing the mathematical formulation of existing macro- and mesoscale friction models to be extended to the nanometric domain.

\section{Acknowledgements}

The work described in this paper is enabled by using the equipment funded via the ERDF project RC.2.2.06-0001 "Research Infrastructure for Campusbased Laboratories at the University of Rijeka RISK", as well as via the support of the University of Rijeka grants uniri-tehnic-18-32 "Advanced mechatronics devices for smart technological solutions" and 4581 "Measuring, modelling and compensating friction in high-precision devices: From macro- to nanometric scale". The work was partially supported also by the Croatian Science Foundation project IP-11-2013-2753 "Laser Cold Plasma Interaction and Diagnostics". The GoSumD software is provided by AIMdyn, Inc.

\section{Appendix 1}

Distribution of measurement points in the considered multidimensional experimental space given by the varying process parameters $F_{\mathrm{N}}, v$ and $\vartheta$ as determined by applying the CVT-based DoE sampling methodology:

\begin{tabular}{ccc}
\hline$F_{\mathrm{N}}(\mathrm{nN})$ & $v(\mathrm{~nm} / \mathrm{s})$ & $\vartheta\left({ }^{\circ} \mathrm{C}\right)$ \\
\hline 74 & 418 & 40 \\
27 & 58 & 27 \\
\hline
\end{tabular}

\begin{tabular}{|c|c|c|}
\hline$F_{\mathrm{N}}(\mathrm{nN})$ & $v(\mathrm{~nm} / \mathrm{s})$ & $\vartheta\left({ }^{\circ} \mathrm{C}\right)$ \\
\hline 86 & 459 & 50 \\
\hline 32 & 438 & 38 \\
\hline 66 & 182 & 44 \\
\hline 72 & 71 & 58 \\
\hline 66 & 311 & 51 \\
\hline 78 & 55 & 36 \\
\hline 108 & 174 & 38 \\
\hline 103 & 297 & 42 \\
\hline 34 & 325 & 57 \\
\hline 107 & 61 & 46 \\
\hline 21 & 176 & 30 \\
\hline 125 & 451 & 26 \\
\hline 137 & 200 & 69 \\
\hline 86 & 215 & 60 \\
\hline 27 & 291 & 42 \\
\hline 76 & 65 & 25 \\
\hline 30 & 79 & 67 \\
\hline 137 & 81 & 76 \\
\hline 72 & 290 & 32 \\
\hline 105 & 442 & 65 \\
\hline 29 & 401 & 74 \\
\hline 91 & 206 & 26 \\
\hline 138 & 358 & 32 \\
\hline 55 & 440 & 58 \\
\hline 136 & 220 & 28 \\
\hline 130 & 74 & 29 \\
\hline 22 & 443 & 56 \\
\hline 54 & 168 & 29 \\
\hline 134 & 117 & 51 \\
\hline 29 & 179 & 51 \\
\hline 131 & 253 & 50 \\
\hline 32 & 59 & 45 \\
\hline 77 & 310 & 72 \\
\hline 103 & 356 & 55 \\
\hline 104 & 188 & 73 \\
\hline 36 & 412 & 25 \\
\hline 113 & 321 & 26 \\
\hline 77 & 442 & 74 \\
\hline 69 & 104 & 74 \\
\hline 128 & 310 & 69 \\
\hline 118 & 56 & 66 \\
\hline 33 & 234 & 71 \\
\hline 135 & 425 & 45 \\
\hline 114 & 452 & 39 \\
\hline 36 & 283 & 28 \\
\hline 77 & 428 & 26 \\
\hline 125 & 431 & 75 \\
\hline 134 & 419 & 59 \\
\hline
\end{tabular}


Open Access: This article is licensed under a Creative Commons Attribution 4.0 International License, which permits use, sharing, adaptation, distribution and reproduction in any medium or format, as long as you give appropriate credit to the original author(s) and the source, provide a link to the Creative Commons licence, and indicate if changes were made.

The images or other third party material in this article are included in the article's Creative Commons licence, unless indicated otherwise in a credit line to the material. If material is not included in the article's Creative Commons licence and your intended use is not permitted by statutory regulation or exceeds the permitted use, you will need to obtain permission directly from the copyright holder.

To view a copy of this licence, visit http://creativecommons.org/licenses/by/4.0/.

\section{References}

[1] Bhushan B. Springer Handbook of Nanotechnology. Berlin, Heidelberg (Germany): Springer-Verlag, 2010.

[2] Marques F, Flores P, Claro J C P, Lankarani H M. A survey and comparison of several friction force models for dynamic analysis of multibody mechanical systems. Nonlinear Dyn 86(3): 1407-1443 (2016)

[3] Mekid S. Precision design aspects for friction actuation with error compensation. J Mech Sci Technol 23(11): 2873-2884 (2009)

[4] Al-Bender F, Lampaert V, Swevers J. Modeling of dry sliding friction dynamics: From heuristic models to physically motivated models and back. Chaos 14(2): 446-460 (2004)

[5] Kamenar E, Zelenika S. Issues in validation of pre-sliding friction models for ultra-high precision positioning. Proc Inst Mech Eng Part C J Mech Eng Sci 233(3): 997-1006 (2019)

[6] Piatkowski T. GMS friction model approximation. Mech Mach Theory 75: 1-11 (2014)

[7] Yoon J Y, Trumper D L. Friction modeling, identification, and compensation based on friction hysteresis and Dahl resonance. Mechatronics 24(6): 734-741 (2014)

[8] Kamenar E, Zelenika S. Nanometric positioning accuracy in the presence of presliding and sliding friction: Modelling, identification and compensation. Mech Based Des Struc Mach 45(1): 111-126 (2017)

[9] Liu Y F, Li J, Zhang Z M, Hu X H, Zhang W J. Experimental comparison of five friction models on the same test-bed of the micro stick-slip motion system. Mech Sci 6(1): 15-28 (2015)
[10] Mate C M. Tribology on the Small Scale: A Bottom Up Approach to Friction, Lubrication, and Wear. Oxford (UK): Oxford University Press, 2007.

[11] De Moerlooze K, Al-Bender F. On the relationship between normal load and friction force in pre-sliding frictional contacts. Part 2: Experimental investigation. Wear 269(3-4): 183-189 (2010)

[12] Krylov S Y, Frenken J W M. The crucial role of temperature in atomic scale friction. J Phys Condens Mat 20(35): 354003 (2008)

[13] Yu J X, Hu H L, Jia F, Yuan W F, Zang H B, Cai Y, Ji F. Quantitative investigation on single-asperity friction and wear of phosphate laser glass against a spherical AFM diamond tip. Tribol Int 81: 43-52 (2015)

[14] Zelenika S. Analytical and experimental characterization of ball-groove contact problems. In Proceedings of the $3^{\text {rd }}$ DAAAM International Conference on Advanced Technologies for Developing Countries, Split, Croatia, 2004: 75-80.

[15] Manini N, Mistura G, Paolicelli G, Tosatti E, Vanossi A. Current trends in the physics of nanoscale friction. Adv Phys 2(3): 569-590 (2017)

[16] University of Rijeka, Croatia. Equipment of the centre for micro- and nanosciences and technologies. http://cmnzt.uniri.hr/wp-content/uploads/2018/04/KatalogCMNZT_ENG.pdf, 2018.

[17] University of Rijeka, Croatia. Centre for micro- and nanosciences and technologies. http://nanori.uniri.hr/, 2018.

[18] Simonovic K, Kalin M. Methodology of a statistical and DOE approach to the prediction of performance in tribology - A DLC boundary-lubrication case study. Tribol Int 101: 10-24 (2016)

[19] Hinkelmann K, Kempthorne O. Design and Analysis of Experiments_Vol. 1: Introduction to Experimental Design. 2nd ed. Hoboken (Belgium): John Wiley \& Sons, 2008.

[20] Alam F M, McNaught K R, Ringrose T J. A comparison of experimental designs in the development of a neural network simulation metamodel. Simul Model Pract Theory 12(7-8): 559-578 (2004)

[21] Du Q, Faber V, Gunzburger M. Centroidal voronoi tessellations: Applications and algorithms. SIAM Rev 41(4): 637-676 (1999)

[22] Kecman V. Learning and Soft Computing: Support Vector Machines, Neural Networks, and Fuzzy Logic Models. Cambridge (USA): MIT Press, 2001.

[23] AIMdyn System Analytics, Engineering Consulting and Software Development. GoSUMD software. https:/aimdyn.com/ gosumd, 2018.

[24] Perčić M, Zelenika S, Mezic I, Peter R, Krstulović N. Experimental approach to establishing a model of nanoscale friction. In Proceedings of the 18th EUSPEN International Conference, Cranfield, UK, 2018: 63-64. 
[25] Yang L, Hu J H, Xiao H P, Quan W W. Analysis of humiditydependent adhesion between a probe tip and a surface. Particuology 33: 91-97 (2017)

[26] Meljanac D, Juraić K, Plodinec M, Siketić Z, Gracin D, Krstulović N, Salamon K, Skenderović H, Kregar Z, Rakić I Š, et al. Influence of RF excitation during pulsed laser deposition in oxygen atmosphere on the structural properties and luminescence of nanocrystalline $\mathrm{ZnO}$ :Al thin films. $J$ Vac Sci Technol A 34(2): 021514 (2016)

[27] Wagner C D, Riggs W M, Davis L E, Moulder J F, Muilenberg G E. Handbook of X-Ray Photoelectron Spectroscopy. Eden Prairie (USA): Perkin-Elmer Corporation, 1979.

[28] Payne B P, Biesinger M C, McIntyre N S. X-ray photoelectron spectroscopy studies of reactions on chromium metal and chromium oxide surfaces. J Electron Spectrosc Relat Phenomena 184(1-2): 29-37 (2011)

[29] Bruker. Stylus Profilometers Dektak XT. https://www.bruker.com/products/surface-and-dimensionalanalysis/stylus-profilometers/dektak-xt/overview.html, 2018.

[30] Bruker. AFM probes SNL-10. https://www.brukerafmprobes. com/p-3693-snl-10.aspx, 2018.

[31] Belikov S, Alexander J, Wall C, Yermolenko I, Magonov S, Malovichko I. Thermal tune method for AFM oscillatory resonant imaging in air and liquid. In Proceedings of 2014 American Control Conference, Portland, OR, USA, 2014: 1009-1014.

[32] Perčić M, Zelenika S, Kamenar E. Issues in validation of friction in the nanometric domain. In Proceedings of the 17th EUSPEN International Conference, Cranfield, UK, 2017: 105-106.

[33] Sader J E. Parallel beam approximation for V-shaped atomic force microscope cantilevers. Rev Sci Instrum 66(9): 4583-4587 (1995)

[34] Zhang X R, Fisher T S, Raman A, Sands T D. Linear coefficient of thermal expansion of porous anodic alumina thin films from atomic force microscopy. Nanosc Microsc Therm Eng 13(4): 243-252 (2009)

[35] MIKROMASCH. Test structures - TGF11 series. https:// www.spmtips.com/test-structures-TGF11-series.html, 2018.

[36] Varenberg M, Etsion I, Halperin G. An improved wedge

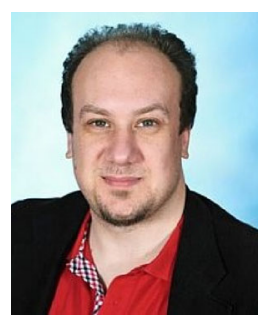

Marko PERČIĆ. He received his master degree in mechanical engineering in 2012 from the Faculty of Engineering of the University of Rijeka, Croatia. He is presently a D. Sc. student at the same University calibration method for lateral force in atomic force microscopy. Rev Sci Instrum 74(7): 3362-3367 (2003)

[37] University of Trieste, Italy. Laboratorio MOSE. http://www. mose.units.it/default.aspx, 2018.

[38] D'Acunto M. Theoretical approach for the quantification of wear mechanisms on the nanoscale. Nanotechnology 15(7): 795-801 (2004)

[39] Liu J J, Notbohm J K, Carpick R W, Turner K T. Method for characterizing nanoscale wear of atomic force microscope tips. ACS Nano 4(7): 3763-3772 (2010)

[40] Bhushan B. Adhesion and stiction: Mechanisms, measurement techniques, and methods for reduction. J Vac Sci Technol B 21(6): 2262 (2003)

[41] Çolak A, Wormeester H, Zandvliet H J W, Poelsema B. Surface adhesion and its dependence on surface roughness and humidity measured with a flat tip. Appl Surf Sci 258(18): 6938-6942 (2012)

[42] Rabinovich Y I, Adler J J, Ata A, Singh R K, Moudgil B M. Adhesion between nanoscale rough surfaces: II. Measurement and comparison with theory. J Colloid Interface Sci 232(1): 17-24 (2000)

[43] Tranchida D, Piccarolo S, Deblieck R A C. Some experimental issues of AFM tip blind estimation: The effect of noise and resolution. Meas Sci Technol 17(10): 2630-2636 (2006)

[44] Bruker. AFM Probes - RS titanium roughness sample. https:// www.brukerafmprobes.com/a-3552-rs.aspx, 2018.

[45] Miller D C, Foster R R, Jen S H, Bertrand J A, Cunningham S J, Morris A S, Lee Y C, George S M, Dunn M L. Thermomechanical properties of alumina films created using the atomic layer deposition technique. Sensor Actuat A Phys 164(1-2): 58-67 (2010)

[46] Mandel J. The Statistical Analysis of Experimental Data. New York (USA): John Wiley \& Sons, 1964.

[47] Dagdeviren O E. Exploring load, velocity, and surface disorder dependence of friction with one-dimensional and two-dimensional models. Nanotechnology 29(31): 315704 (2018)

[48] Tambe N S, Bhushan B. Friction model for the velocity dependence of nanoscale friction. Nanotechnology 16(10): 2309-2324 (2005)

working on nanoscale characterization of materials. $\mathrm{He}$ is staff member of the Centre for Micro- and Nanosciences and Technologies of the University of Rijeka. His research interests include experimental nanotribology, atomic force microscopy, thin films, mathematical modelling and data mining. 


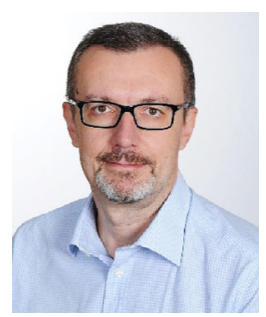

Saša ZELENIKA. He graduated at the University of Rijeka, Croatia and attained the D. Sc. degree at the Polytechnic University of Turin, Italy. He was Head of Mechanical Engineering at the Paul Scherrer Institute in Switzerland. From 2004 he is faculty member of the University of Rijeka, Faculty of Engineering (since 2015 full professor with

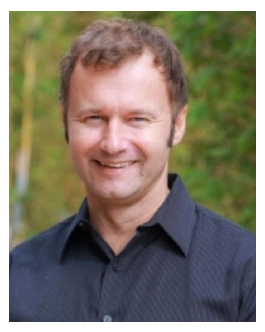

Igor MEZIĆ. He graduated at the University of Rijeka, Croatia and got the Ph.D. degree from Caltech. He was postdoctoral fellow at the University of Warwick, UK, joined the University of California (UC), Santa Barbara and moved to Harvard University before returning to UC Santa Barbara, where he became a full professor in 2003. He holds numerous awards and honors in the fields of physics, mathematics (Sloan Fellowship)

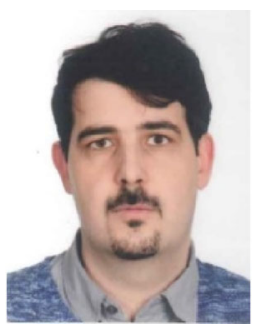

Robert PETER. He received his master degree at the University of Rijeka, Croatia and the D. Sc. degree at the University of Zagreb, Croatia. From 2016 he is employed as assistant professor at the

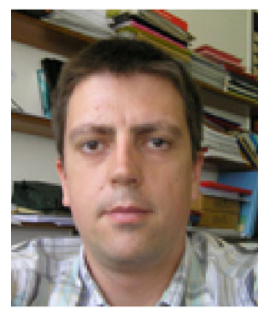

Nikša KRSTULOVIĆ. He received his Ph.D. degree in physics at the University of Zagreb, Croatia. He is employed at the Institute of Physics, Zagreb, Croatia where he is leader of the Plasma Unit Group of the Centre of Advanced Laser Techniques (CALT). He spent two years on a postdoc tenure) where he was dean's assistant, department head and is laboratory head. In 2012-2014 he was Assistant and then Deputy Minister at the Croatian Ministry of Science, Education and Sports. Currently he is Rector's Assistant and Head of the Centre for Micro- and Nanoscience and Technologies at the University of Rijeka. His research interests encompass precision engineering and microsystems technologies.

and engineering. He is Fellow of the American Physical Society and of the Society for Industrial and Applied Mathematics. He holds 4 US patents, and 3 technological companies (Ecorithm, iFluidics and AIMdyn) were founded on the basis of his patents and algorithms. He is currently professor at the Department of Mechanical Engineering at UC Santa Barbara and chief scientist at Packetsled, Inc. His research interests are in developments in operator theory, machine learning and artificial intelligence.

Department of Physics and the Centre for Micro- and Nanosciences and Technologies at the University of Rijeka. His research interests include physics of semiconductor surfaces and the development and characterization of metal oxide nanostructures.

position at the University College Dublin under a Marie Curie fellowship working on EUV light sources. His research interests include laser produced and nonequilibrium plasmas, atmospheric plasmas, plasma diagnostics, high-harmonic generation, extreme light sources, synthesis and applications of nanoparticles by laser ablation in liquids and PLD of thin films. 